\title{
Clinical accuracy of post graduate student in diagnosing congenital heart diseases (CHD) using an algorithmic approach and its comparison with echocardiography
}

\author{
Mehta N. ${ }^{1}$, Bhalse S. ${ }^{2}$ \\ ${ }^{1}$ Dr. Nirbhay Mehta, Associate Professor, Department of Pediatrics, ${ }^{2}$ Dr. Swati Bhalse, Senior Resident, both authors are \\ affiliated with Department of Pediatrics, MGM Medical College Indore, MP, India.
}

Corresponding Author: Dr. Nirbhay Mehta, Department of Pediatrics, MGM Medical College Indore. E-mail: drnirbhaymehta@gmail.com, swatibhalse27@gmail.com

\begin{abstract}
Background: Congenital heart diseases (CHDs)are an important cause of morbidity and mortality in children. In view of poor availability of resources in developing nations like India, clinical evaluation of children with CHD is important. Aim: To study the clinical accuracy of post graduate student in diagnosing congenital heart diseases and its comparison with echocardiography. Subjects and Methods: A prospective cross-sectional study performed in the Department ofPediatrics of a tertiary level teaching hospital in central India. Participants were children with CHDs attending outpatient department or admitted in wards or PICU. History, general physical and cardiovascular examinations were recorded by the post graduate student. Chest X-ray and ECG were obtained. These findings were used to classify the defect using an algorithm and a clinical diagnosis was made which was matched with echocardiography.Kappa coefficient test was used to judge the degree of agreement between the two methods. Results: 80 patients with CHDs were included in the final analysis. 49 (61.25\%) had acyanotic CHDs and ventricular septal defect (VSD) was the most common defect $(n=24,30 \%)$ while tetralogy of Fallot (TOF) was the most common $(n=14,17.5 \%)$ cyanotic CHD. Concordance of clinical diagnosis and echocardiography was maximum for VSD (16/24, 66.6\%) in acyanotic group and TOF $(8 / 14,57 \%)$ in cyanotic group. Kappa's coefficient test analysis also showed an "almost perfect" area of agreement for VSD $(\kappa=0.87)$ and fair area of agreement for TOF $(\kappa=0.65)$. For type of CHD (cyanotic or acyanotic) and type of ventricular hypertrophy (left, right or biventricular) it showed "almost perfect" and"fair" area of agreement respectively. Conclusion: Agreement between echocardiography and cclinical diagnosis of CHDs including hemodynamic parameters like type of ventricular hypertrophy and pulmonary arterial hypertension was reasonably accurate in our study.
\end{abstract}

Key words: Congenital heart disease, Clinical diagnosis, Echocardiography

\section{Introduction}

Incidence and prevalence of congenital heart diseases (CHDs) varies in different geographical areas. According to a large hospital-based study from India, the incidence of congenital heart disease is $3.9 / 1000$ live births [1]. In community-based studies from India the prevalence of CHD ranges from $0.8-5.2 / 1000$ patients $[2,3]$. As the incidence of rheumatic fever and rheumatic heart diseases is declining in developing nations including India, CHDs are becoming an important cause of cardiac morbidity and mortality in infants and children [4]. Approximately 3\% of

Manuscript received: $25^{\text {th }}$ February 2018

Reviewed: $6^{\text {th }}$ March 2018

Author Corrected: $14^{\text {th }}$ March 2018

Accepted for Publication: $17^{\text {th }}$ March 2018 childhood mortality in India can be attributed to congenital malformations and CHDs are one of the common congenital anomalies seen [5]. In low- and middle-income countries, timely diagnosis and repair of CHDs is not feasible for a variety of reasons [6].

According to a recently published report, approximately $90 \%$ of children born with CHD in Asia and Africa have no or minimal access to healthcare, which ultimately results in a much higher child mortality rate compared with the rest of the world [7]. In such a situation proper evaluation, initiation of management and timely referral of such children can improve their outcome.Importance of training during the post- 
graduation period for developing such skills cannot be over emphasized. The purpose of the present study was to evaluate the clinical skills of pediatric post graduate student in diagnosing CHDs using simple tools like history, physical examination, ECG and chest X- ray and compare it with the echocardiography.

\section{Methods}

This was a prospective cross-sectional study carried out in the department of Pediatrics at tertiary care level teaching hospitals in central India from March 2014 to August 2015.

Subject Selection: Children aged 1 month to 12 years of age attending the outpatient department or admitted in the hospital with clinical signs and symptoms suggestive of CHDs were included in the study.

Exclusion Criteria: Children with CHD in whom anatomical diagnosis by echocardiography was already done were excluded.

Study Design: Detailed history and physical examination, including cardiovascular examination, of study patients were recorded in a proforma by the post graduate student (PGS). An X-ray chest (standard PA view) was done and film was evaluated for presence of cardiomegaly, pulmonary vascularity and individual chamber enlargement. Note of any other pulmonary or skeletal abnormality was made. A standard 12 lead pediatric ECG was taken. Algorithm for classification of CHDs (Fig. 1 A and 1B) [8] was used to make a clinical diagnosis of an anatomical defect/ a list of possible defects. A 2D pediatric echocardiography with colour Doppler was done by a cardiologist trained in the procedure and blinded for the clinical findings.

Statistical Analysis: Agreement between the two methods was done using kappa coefficient test.Cohen's kappa coefficient $(\kappa)$ is a measure of inter-rater agreement for qualitative (categorical) items. This is calculated as follows: $\boldsymbol{\kappa}=\mathbf{p}_{\mathbf{0}}-\mathbf{p}_{\mathrm{e}} / \mathbf{1 - p _ { \mathrm { e } }}$

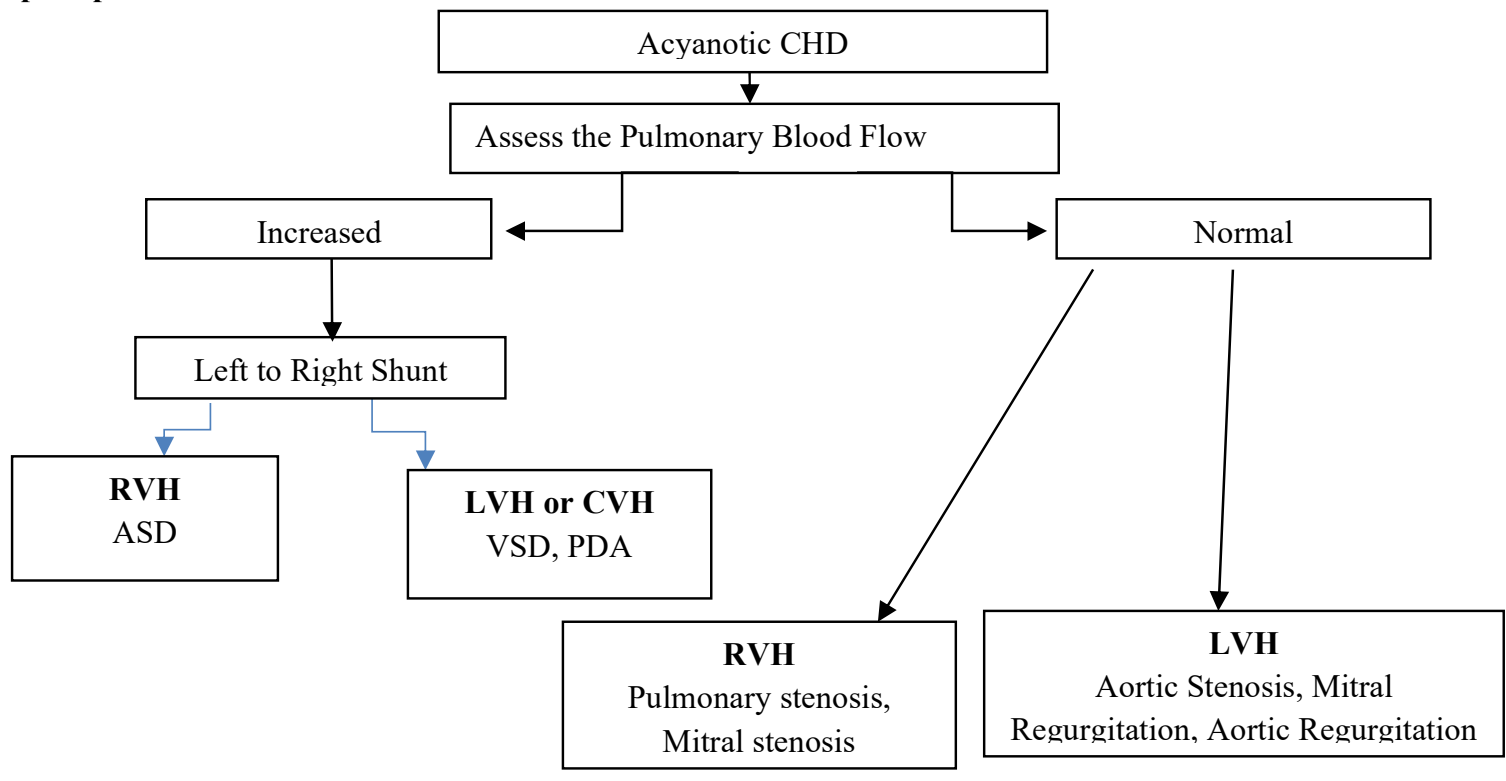

Figure 1(A): Algorithm for Clinical Diagnosis of Acyanotic Congenital Heart Diseases

Abbreviations Used: ASD- Atrial Septal Defect, RVH- Right Ventricular Hypertrophy, VSD-Ventricular Septal Defect, LVH- Left Ventricular Hypertrophy, PDA- Patent Ductus Arteriosus, CVH- Combined Ventricular Hypertrophy

Where $p_{o}$ is the relative observed agreement among raters, and $p_{e}$ is the hypothetical probability of chance agreement. If the raters are in complete agreement, then $\kappa=1$. If there is no agreement among the raters other than what would be expected by chance (as given by $p_{e}$ ), $\kappa \leq 0$. Kappa over 0.75 is considered as excellent, 0.40 to 0.75 as fair to good, and below 0.40 as poor[9,10].In our study we calculated $\kappa$ values separately for type of CHD (acyanotic or cyanotic), ventricular hypertrophy $(\mathrm{RVH} / \mathrm{LVH} / \mathrm{BVH})$, and presence or absence of pulmonary hypertension. 


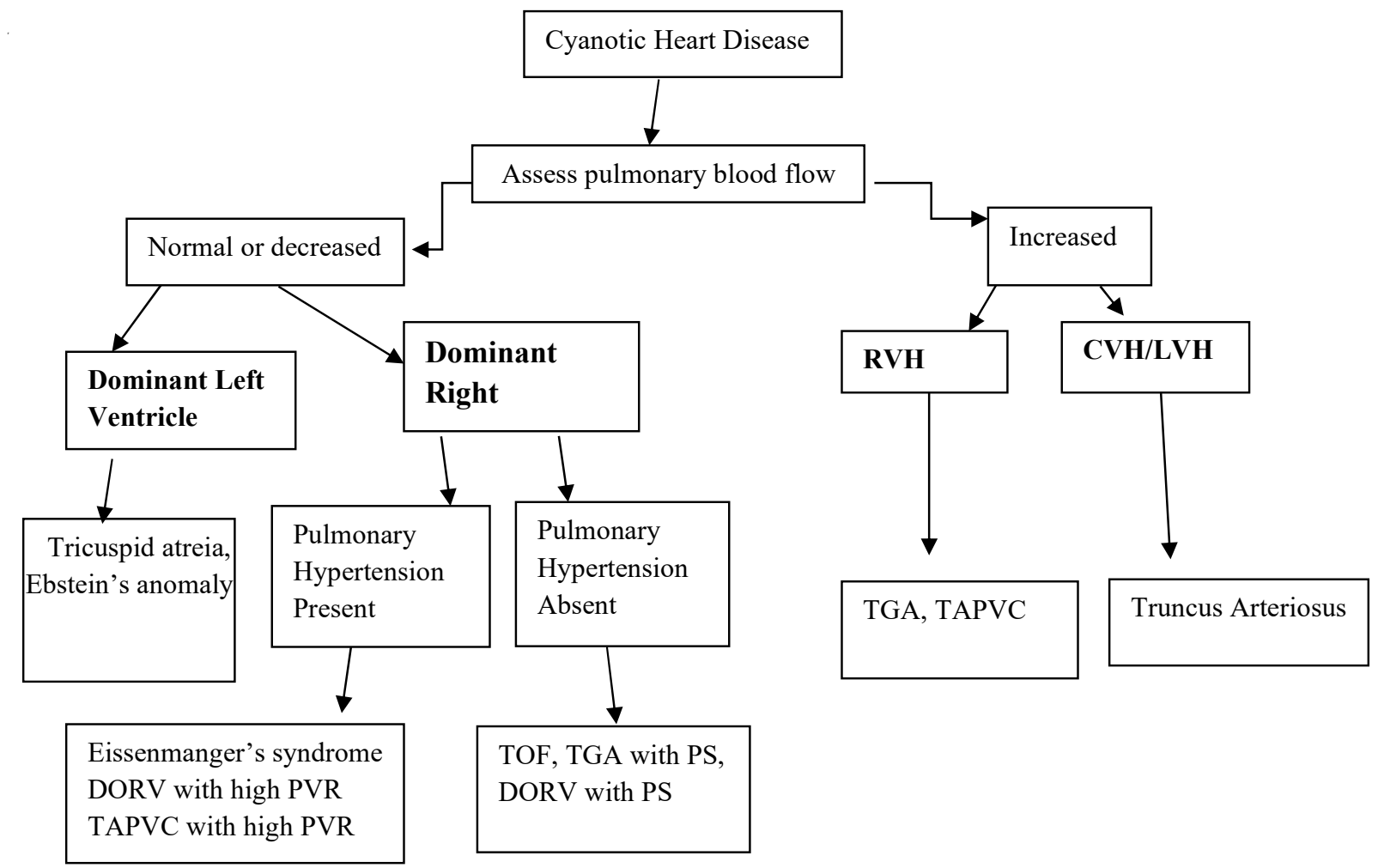

Figure 1 (B): Algorithm for Clinical Diagnosis of Cyanotic Congenital Heart Diseases

Abbreviations used: DORV- Double Outlet Right Ventricle, TAPVC- Total Anomalous Pulmonary Venous Connection, PVR- Pulmonary Vascular Resistance, TOF- Tetralogy of Fallot, TGA- Transposition of great arteries PSPulmonary stenosis, RVH- Right Ventricular Hypertrophy, LVH- Left Ventricular Hypertrophy, CVH- Combined Ventricular Hypertrophy

\section{Results}

91 patients with CHD were enrolled for the study. 11 were excluded due to failure to give the written consent or because their echocardiography was already done.

Thus 80 patients were included in the final analysis. Most patients $(n=69,86 \%)$ were between age 1 month to 1 year. Acyanotic defects were present in 49 children $(61.25 \%)$ and 31 had cyanotic defects.

Among the acyanotic group, most cases were of ventricular septal defect (VSD) ( $\mathrm{n}=24,30 \%)$, followed by endocardial cushion defect (ECD), patent ductus arteriosus (PDA) and atrial septal defect (ASD), while tetralogy of Fallot (TOF), transposition of great arteries (TGA) and tricuspid atresia were the commonly occurring cyanotic defects(Table 1)

When agreement between the clinical diagnosis and echocardiography was studied, accuracy of clinical diagnosis for type of CHD (cyanotic or acyanotic) showed "almost perfect" area of agreement as per kappa's coefficient test $(\kappa>0.75)$, while that for type of ventricular hypertrophy and presence of pulmonary arterial hypertension showed "fair" area of agreement $(\kappa=0.4-0.75)$.

As far as diagnosis of individual defects is concerned, better agreement was observed for acyanotic CHDs than cyanotic ones. Accuracy was found to be best for VSD in acyanotic group $(\kappa=0.89)$ and TOF in cyanotic group $(\kappa=0.65)$.

Table 2 shows the degree of agreement between the clinical algorithmic method and echocardiography in percentage terms indicating the sensitivity of algorithmic approach for detecting various lesions.

Clinical diagnosis of relatively rare and complex type of defects could not be made by the PGS. 
Table-1: Distribution of CHDs in the study

\begin{tabular}{|c|c|}
\hline Defect & Number of cases \\
\hline Acyanotic CHDs: & $\mathbf{4 9}$ \\
Ventricular septal defect & 24 \\
\hline Endocardial cushion defect & 6 \\
\hline Patent ductus arteriosus & 5 \\
\hline Pulmonary stenosis & 2 \\
\hline Atrial septal defect & 1 \\
\hline Cor triatriatum with dilated LAD & 1 \\
\hline Bicuspid aortic valve + Severe AS+ PDA & $\mathbf{3 1}$ \\
\hline Cyanotic CHDs: & 14 \\
\hline Tetrology of Fallot & 6 \\
\hline Transposition of great arteries with VSD & 5 \\
\hline Tricuspid atresia with VSD & 3 \\
\hline DORV +VSD & 1 \\
\hline TAPVR & 1 \\
\hline Truncusarteriosus & 1 \\
\hline Ebsteins anomaly & \\
\hline
\end{tabular}

Table-2: Degree of agreement between clinical and echocardiographic diagnosis of common CHDs

\begin{tabular}{|c|c|c|c|}
\hline Name of CHD & $\begin{array}{c}\text { Number of cases } \\
\text { Diagnosed Clinically } \\
\text { A }\end{array}$ & $\begin{array}{c}\text { Number of cases Diagnosed } \\
\text { Echocardiographically } \\
\text { B }\end{array}$ & $\begin{array}{c}\text { Agreement between A } \\
\text { and B } \\
\text { (A/B X 100) }\end{array}$ \\
\hline VSD & 16 & 24 & $66.6 \%$ \\
\hline TOF & 8 & 14 & $57 \%$ \\
\hline ECD & 4 & 10 & $40 \%$ \\
\hline PS & 2 & 5 & $40 \%$ \\
\hline PDA & 2 & 6 & $33.3 \%$ \\
\hline TGA & 2 & 6 & $33 \%$ \\
\hline Tricuspid atresia & 1 & 5 & $20 \%$ \\
\hline ASD & 0 & 2 & $0 \%$ \\
\hline
\end{tabular}

\section{Discussion}

For many years clinical judgment has been a useful diagnostic tool and a key component of the patientphysician interaction [11]. However, with the frequent availability of advanced medical technologies, efforts in making clinical judgment and precision in making a bed side clinical diagnosis have taken a major setback, specially in resource rich situations. Bed-side evaluation of a child with congenital heart disease is important for several reasons: accuracy of diagnosis for initiation of treatment before the confirmation by echocardiography, physician's intellectual satisfaction, parental confidence in the physicians, and appropriate cost-effective use of medical resources [12].

We conducted this study to assess the accuracy of clinical diagnosis of congenital heart diseases made by the post graduate student by comparing it with echocardiography. Various studies have been done in children and adults where clinical judgment was compared with the echocardiography for diagnosis of various cardiac disorders $[12,13,14,15]$. We studied 80 cases ofcongenital heart diseases from 1 month to 12 years of age. Acyanotic CHDs were more common than cyanotic CHDs. The distribution of various defects in our study was similar to that found in other studies $[16,17,18,19]$.

Among acyanotic group, ventricular septal defect, endocardial cushion defect, patent ductus arteriosus and atrial septal defect were the most commonly diagnosed conditions. Tetralogy of Fallot, d-TGA and tricuspid atresia were the common cyanotic CHDs in our study. Presence of cyanosis was detected clinically in 32 patients, out of which echocardiography showed cyanotic CHD in 31 patients. Hence only 1 patient who was a case of acyanotic CHD was clinically judged as 
cyanotic CHD. There was an "almost perfect" agreement $(\kappa>0.75)$ between clinical diagnosis and echocardiography for categorizing the defect as acyanotic and cyanotic. Though we did not use the pulse oximetry for determination of cyanosis in our study, newborn screening for critical congenital heart disease (CCHD) using pulse oximetry has been endorsed by the AAP and the AHA. The recommended screening requires two saturation readings [20].

Recently a modified screening algorithm with 1 repeat pulse oximetry test instead of 2 was found to detect additional infants with significant disease without a substantial increase in the false-positive rate [21].

For diagnosis of type of ventricular hypertrophy/ dominance (left or right) and for pulmonary hypertension $(\mathrm{PH})$, there was a "fair" and "moderate" area of agreement respectively between method used by the PGS and echocardiography. In a study done by Elgendi $\mathrm{M}$ et al [22] authors analyzed the heart sounds in terms of various qualities like frequency band, energy of the sinusoid formants, and entropy using a digital stethoscope for detection of pulmonary hypertension.

The pattern analysis done in their study revealed a unique sound signature in patients with pulmonary hypertension. They concluded that this method can be used in non-invasive screening tools for pulmonary hypertension. In a mixed-method study published by Colman and colleagues[14], the physical sign with the highest likelihood ratio (LR) for diagnosing $\mathrm{PH}$ was a loud P2 on inspiration with a LR +ve $1.9,95 \%$ CI [1.2, 3.1] but authors found that no aspect of the physical exam could consistently rule out PH (negative LRs $0.7-$ 1.3).

They concluded that the presence of a loud P2 or audible right-sided 4th heart sound are associated with $\mathrm{PH}$, however the physical examination was unreliable for determining the presence of $\mathrm{PH}$. Some studies done in adult patients have compared the clinical evaluation of abnormal cardiac physiology with echocardiography $[23,24]$.

Researchers in these studies have shown that the bedside cardiovascular examination in the patients with chronic heart failure was extremely useful in identifying patients with elevation of right and left heart pressures. History of orthopnea and presenceof jugular venous distension at rest or by the abdominojugular test was found to be simple and highly sensitive and specific in assessing left heart pressures in these patients.
As far as anatomical diagnosis of individual lesions is concerned, clinical diagnosis of VSD was made in 16 out of 24 cases diagnosed echocardiographically, sensitivity being $66.6 \%$. This was $57 \%$ for TOF and $33 \%$ for PDA and TGA. In study done by Subhi [12], diagnostic accuracy of clinical diagnosis was compared with the echocardiography in evaluating children with heart murmurs. It was found that both the diagnoses were concordant in $52.3 \%$ of patients and discordant in $47.7 \%$.

Similar to our results, he also found VSD as the most concordant diagnosis. Kappa coefficient test showed a perfect agreement between the two methods for diagnosis of VSD $(\kappa=0.89)$ in our study. In a study published by Patel et al authors found almost perfect agreement between clinical and echocardiographic detection for VSD $(\mathrm{k}=0.872)$, though the subjects in their study were adult patients with both congenital and acquired cardiac diseases.

In one study done at a tertiary center in central India [18], authors reported that clinically diagnosed cases were found to correlate with echo diagnosis completely in $72.4 \%$ of cases, partially in $13.27 \%$ of cases and wrong in $14.29 \%$ of cases.

Thus, clinical evaluation of patients with CHDs is a reasonably accurate method to understand the underlying pathophysiological and anatomical derangement. The reported defect in accuracy of the clinical diagnosis probably reflects the training skills and experiences of the clinicians.

Teaching medical institutes should pursue the development, implementation and evaluation of advanced physical diagnosis curriculum for medical students and establish specific training programs in cardiology for pediatricians.

Limitations: Limited study period, evolving clinical skills of PGS during training and single center study are the major limitations of our study which can confound the final results.

\section{Summary and Conclusions}

Clinical diagnosis of CHDs in children using an algorithmic approach with the use of chest x-ray and ECG correlates well with the results of echocardiography. The accuracy for making anatomical diagnosis was found to be better for acyanotic CHDs than cyanotic ones. Assessment of hemodynamic parameters like type of ventricular hypertrophy and presence of 
pulmonary arterial hypertension were found to correlate well with results obtained by echocardiography.

\section{What This Study Adds}

1. Findings of history, physical examination along with ECG and chest X-ray can help in reaching to a reasonably accurate clinical diagnosis of CHDs.

2. Accuracy of clinical diagnosis varies with the type of CHD.

Contributors:NM conceptualized the study and drafted the manuscript. SB collected and analyzed the data. Both the authors contributed to the critical revision of the manuscript, and its final approval.

Funding: Nil, Conflict of interest: None initiated, Perission from IRB: Yes

\section{References}

1. Khalil A, Aggarwal R, Thirupuram S, Arora R. Incidence of congenital heart disease among hospital live births in India. Indian Pediatr. 1994 May;31 (5): 519-27.

2. Gupta I, Gupta ML, Parihar A, Gupta CD. Epidemiology of rheumatic and congenital heart diseases in school children. J Indian Med Assoc. 1992 Mar; 90 (3):57-9.

3. Vashishtha VM, Kalra A, Kalra K, Jain VK. Prevalence of congenital heart disease in school children. Indian Pediatr 1993; 30: 1337-1340.

4. Jose VJ, Gomathi M. Declining prevalence of rheumatic heart disease in rural schoolchildren in India: 2001-2002. Indian Heart J.2003 Mar-Apr;55(2):158-60.

5. Lahariya C, Paul VK. Burden, differentials, and causes of child deaths in India. Indian J Pediatr. 2010 Nov;77 (11): 1312-21. doi: 10.1007/s12098-010-0185z. Epub 2010 Sep 10.

6. Iyer PU, Moreno GE, Fernando Caneo L, Faiz T, Shekerdemian LS, Iyer KS. Management of late presentation congenital heart disease. Cardiol Young. 2017 Dec;27(S6):S31-S39. doi: 10.1017/S104795111 7002591 .

7. Saxena A. Pediatric cardiac care in India: current status and the way forward. Future Cardiol. 2018 Jan;14(1):1-4. doi: 10.2217/fca-2017-0084. Epub 2017 Nov 23.
8. Joseph $\mathrm{K}$ Perloff. The clinical recognition of congenital heart disease. $3^{\text {rd }}$ ed. New Delhi: Jaypee Brothers; 1988. Chapter 1, Introduction: formulation of the problem; p1-7.

9. McHugh ML. Interrater reliability: the kappa statistic. Biochem Med (Zagreb). 2012; 22 (3): 276-82.

10.Viera AJ, Garrett JM. Understanding interobserver agreement: the kappa statistic. Fam Med. 2005 May; 37 (5): 360-3.

11.Subhi MD. Diagnostic accuracy of clinical diagnosis versus echo cardio graphy in evaluating heart murmurs in Iraqi children. Saudi Med J 2006; 27 (5): $672-675$

12.Gessner IH. What makes a heart murmur innocent? Pediatr Ann. 1997 Feb;26(2):82-4, 87-8, 90-1.

13. Patel A, Tomar NS, Bharani A. Utility of physical examination and comparison to echocardiography for cardiac diagnosis. Indian Heart Journal 2017; 69: $141-145$

14.Colman R, WhittinghamH, Tomlinson G, Granton J. Utility of the Physical Examination in Detecting Pulmonary Hypertension. A Mixed Methods Study. PLOS ONE 2014;10(9): e108499.

15.Reddy A, Jatana SK, Nair MNG. Clinical evaluation versus echocardiography in the assessment of rheumatic heart disease. MJAFI 2004; 60 : 255-258

16. Kapoor R, Gupta S. Prevalence of congenital heart disease, Kanpur, India. Indian Pediatr. 2008 Apr;45 (4):309-11.

17. SalahAIbrahim, MohammedH.Abdelrahman,Osama $\mathrm{H}$ Elshazali. Pattern anddiagnosis of congenital heart disease in patients attending AhemadGasim Cardiac Center. Sudan JMS 2012 Dec; 7(4):249-254.

18. Reddy R, Taksande A. Clinical profile of congenital heart disease in a tertiary care hospital in central India. Journal of Datta Meghe Institute of Medical Sciences University 2016 Jun; 11(1): 81-86

19. Ashraf M, Chowdhary J, Khajuria K, Reyaz AM. Spectrum of congenital heart diseases in Kashmir, India. Indian Pediatr. 2009 Dec; 46 (12): $1107-8$ 
20. Kemper AR, Mahle WT, Martin GR, Cooley WC, Kumar P, Morrow WB, et al. Strategies for implementing screening for critical congenital heart disease. Pediatrics 2011; 128(5):1259-1267.

21. Diller CL, Kelleman MS, Kupke KG, Quary SC, Kochilas LK, Oster ME. A Modified Algorithm for Critical Congenital Heart Disease Screening Using Pulse Oximetry. Pediatrics. 2018 May;141(5). pii: e 20174065. doi: 10.1542/peds.2017-4065.

22. Elgendi M, Bobhate P, Jain S, Guo L, Rutledge J, Coe $\mathrm{Y}$ et al. The voice of the heart: vowel-like sound in pulmonary artery hypertension. Diseases 2018 Apr 13; $6(2)$ : e26.
23. Butman SM, Ewy GA, Standen JR, Kern KB, Hahn E. Bedside cardiovascular examination in patients with severechronic heart failure: importanceofrest or inducible jugular venous distension. J Am Coll Cardiol. 1993Oct; 22(4):968-74.

24. Drazner MH, Hellkamp AS, Leier CV, Shah MR, Miller LW, Russell SD, Young JB, Califf RM, Nohria A. Value of clinicianassessment of hemodynamics in advancedheart failure: the ESCAPE trial. Circ Heart Fail.2008Sep;1(3):170-7. doi: 10.1161/CIRCHEART FAILURE. 108.769778.

\section{How to cite this article?}

Mehta N, Bhalse S. Clinical accuracy of post graduate student in diagnosing congenital heart diseases (CHD) using an algorithmic approach and its comparison with echocardiography. Int J Pediatr Res. 2018;5(3):149-155.doi:10. 17511/ijpr.2018.i03.08. 